\title{
(6) OPEN ACCESS \\ Keeping children safe at home: protocol for three matched case-control studies of modifiable risk factors for falls
}

\author{
Denise Kendrick, ${ }^{1}$ Asiya Maula, ${ }^{1}$ Jane Stewart, ${ }^{2}$ Rose Clacy, ${ }^{1}$ Frank Coffey, ${ }^{3}$ \\ Nicola Cooper, ${ }^{4}$ Carol Coupland, ${ }^{1}$ Mike Hayes, ${ }^{5}$ Elaine McColl, ${ }_{9}^{6}$ Richard Reading, ${ }^{7}$ \\ Alex Sutton, ${ }^{4}$ Elizabeth M L Towner, ${ }^{8}$ Michael Craig Watson, ${ }^{9}$ on behalf of the \\ Keeping Children Safe Study Group*
}

${ }^{1}$ Division of Primary Care, Tower Building, University Park, Nottingham, UK

${ }^{2}$ Nottinghamshire Healthcare NHS Trust, Nottingham, UK ${ }^{3}$ Nottingham University Hospitals NHS Trust, Queen's Medical Centre, Nottingham, UK ${ }^{4}$ Department of Health Sciences, University of Leicester, Leicester, UK

${ }^{5}$ Child Accident Prevention Trust, Child Accident Prevention Trust, London, UK

${ }^{6}$ Newcastle Clinical Trials Unit, The Medical School, Newcastle University, Newcastle upon Tyne, UK

${ }^{7}$ Norfolk and Norwich University Hospital, Colney Lane, Norwich, UK

${ }^{8}$ Centre for Child and Adolescent Health, University of the West of England, Bristol, UK ${ }^{9}$ School of Nursing, Nottingham University Hospitals NHS Trust, Queen's Medical Centre

Nottingham, UK

Correspondence to Dr Asiya Maula, Division of Primary Care, Tower Building, University Park, Nottingham NG7 2RD, UK;

asiya.maula@nottingham.ac.uk

*The Keeping Children Safe Study Group is listed in appendix 1 .

Accepted 14 March 2012

\section{ABSTRACT}

Background Childhood falls result in considerable morbidity, mortality and health service use. Despite this, little evidence exists on protective factors or effective falls prevention interventions in young children.

Objectives To estimate ORs for three types of medically attended fall injuries in young children in relation to safety equipment, safety behaviours and hazard reduction and explore differential effects by child and family factors and injury severity.

Design Three multicentre case-control studies in UK hospitals with validation of parental reported exposures using home observations. Cases are aged $0-4$ years with a medically attended fall injury occurring at home, matched on age and sex with community controls. Children attending hospital for other types of injury will serve as unmatched hospital controls. Matched analyses will use conditional logistic regression to adjust for potential confounding variables. Unmatched analyses will use unconditional logistic regression, adjusted for age, sex, deprivation and distance from hospital in addition to other confounders. Each study requires 496 cases and 1984 controls to detect an OR of 0.7, with 80\% power, $5 \%$ significance level, a correlation between cases and controls of 0.1 and a range of exposure prevalences.

Main outcome measures Falls on stairs, on one level and from furniture.

Discussion As the largest in the field to date, these case control studies will adjust for potential confounders, validate measures of exposure and investigate modifiable risk factors for specific falls injury mechanisms. Findings should enhance the evidence base for falls prevention for young children.

\section{INTRODUCTION}

Falls are a leading cause of morbidity and mortality in childhood. ${ }^{1-3}$ Globally in 2004, $4.2 \%$ of all deaths worldwide in 0-17 year olds were attributed to falls. ${ }^{4}$ Fatal fall rates in those under 20 years of age vary by country, income and gender with the highest rates seen in Eastern Mediterranean and South East Asian regions. ${ }^{4}$ Falls are the 4th leading cause of injury-related death in children in the USA $^{5}$ and the 6 th leading cause of injury-related death in children aged $0-14$ years in Australia. ${ }^{6}$

Falls are the 13th most common cause of disability-adjusted life years (DALY) lost world- wide. ${ }^{7}$ Globally, $50 \%$ of the total number of DALYs lost due to falls occur in children younger than 15 years. ${ }^{4}$ In one UK study falls accounted for $60 \%$ of traumatic brain injuries in those under 5 years. ${ }^{9}$ In the UK and France they are the most common cause of fatal and serious head injuries $^{10-12}$ and in China they are the leading cause of permanent disability in children aged 0-17 years. ${ }^{13}$ Beyond the age of infancy, children typically use their arms to shield their head; consequently falls result in limb fractures, most commonly of the forearm. ${ }^{14-18}$

In most countries falls are the most common cause of childhood attendance at emergency departments (EDs) accounting for $22 \%$ to $52 \%$ of attendances. ${ }^{78}$ In the UK falls accounted for more than 47000 hospital admissions in 2009/2010 in children aged $0-14$ years. ${ }^{19}$ Falls account for between $25 \%$ and $50 \%$ of all hospital admissions in low-income and middle-income countries and these rates are thought to be under-reported. ${ }^{72}$ The burden placed on healthcare resources is substantial: the annual cost of childhood falls in Canada in 1995 was 630 million Canadian dollars, in Australia in 1994 annual child fall injury costs were estimated at over 130 million Australian dollars and in the USA in 1996 falls were responsible for approximately one-quarter of all childhood unintentional injury-related costs. ${ }^{6} 2122$

Childhood falls frequently occur from structural components of houses; commonly stairs, balconies and walls. ${ }^{3}$ Under the age of 1 , aside from being dropped, falls commonly occur from furniture or car seats; and from steps, staircases or play equipment in 1-3 year olds. ${ }^{23-27}$ Older children aged 5-17 are more likely to fall from objects such as playground equipment. ${ }^{24}$

A systematic review of risk factors for fall-related injuries in children aged $>7$ years old found few controlled studies. Low socioeconomic status, male sex and young age were consistently found to be risk factors in high-income and low-to-middleincome countries. ${ }^{7}$ Other risk factors included the height of the fall, the surface onto which the child fell and the mechanism of fall. ${ }^{7}$ The review recommended that population-based case-control studies examining risk and protective factors for childhood fall injuries were needed. A more recent systematic review found falls to be associated with lower socioeconomic status, parental education and 
income, but effects varied across age ranges, gender and mechanism of fall. ${ }^{28-30}$

Case-control studies have examined risk and protective factors for a range of childhood injuries. However, these are often hampered by limitations such as small sample size, use of hospital controls rather than community controls, controlling for a limited range of confounders, the use of non-validated measures of exposure, the use of composite exposure measures precluding estimation of protective effects of individual safety behaviours and a lack of specificity in case definition. ${ }^{31-36}$ Evidence from well designed and executed case-control studies such as those examining the protective effects of cycle helmets $^{37}$ and smoke alarms ${ }^{38}$ has played a highly influential role in policy development and legislation. Similar evidence is now required for potentially modifiable factors for falls prevention in childhood.

The aim of the case-control studies described here is to evaluate the relationship between modifiable risk factors (eg, safety equipment use, behaviours and home hazards) and fall injuries in young children. Limitations of previous studies will be addressed by undertaking separate case-control studies for three common fall mechanisms: falls from furniture, falls down stairs and falls on the same level. Community and hospital controls will be used, a range of confounding factors will be measured and adjusted for and parental reported exposures will be validated by home observations in a sample of cases and controls.

\section{METHODS}

\section{Objectives}

The primary objective is to estimate ORs for three types of medically attended falls (either from furniture, down stairs or on one level) occurring in children under the age of 5 years for a range of modifiable risk factors including safety behaviours, safety equipment use and hazards and to adjust for a range of potential confounding factors. Secondary objectives are to explore effects of safety equipment, safety behaviours and hazard reduction by child and family factors which may be associated with differential effectiveness of home safety interventions (child age, gender, ethnicity, single parenthood, housing tenure and unemployment) ${ }^{39}$ and injury severity.

\section{Study design}

Three multicentre matched case-control studies will be undertaken within hospitals in Nottingham, Bristol, Norwich, Newcastle-upon-Tyne, Gateshead, Derby and Great Yarmouth, UK, with recruitment commencing on 14 June 2010.

\section{Definitions of cases and controls}

A fall is defined as: 'an event which results in a person coming to rest inadvertently on the ground or floor or other lower level'. ${ }^{40}$ Medically attended fall injuries (MAFI) are falls resulting in hospital admission, ED, or Minor Injury Unit (MIU) attendance.

Cases will be defined as children aged $0-4$ years attending one of the participating hospitals or MIUs with a MAFI resulting from a stairway fall, fall from furniture or fall on one level that occurred in the home or garden at the address where the child is registered with a general practitioner (GP) (hereafter referred to as the child's home or garden).

Children with intentional or suspected intentional injury, those living in residential care and those who suffered fatal injuries will be excluded. Cases who have a further MAFI 12 months or more after being recruited to one of the studies will be eligible for inclusion as a case if they present with a fall with a different mechanism from the fall that resulted in their initial study recruitment. Cases will be recruited to a maximum of two of the case-control studies. Cases will not be eligible to be subsequently recruited as controls.

Controls will be defined as children aged $0-4$ years who did not have a MAFI on the same date as the cases' attendance or admission to hospital. Children living in residential care will be excluded. Controls will be eligible for subsequent recruitment to the three studies as a case, or as a further control if they are recruited 12 months or more after their first recruitment. Controls will not be recruited more than twice to any of the three case-control studies.

\section{Recruitment of cases and controls}

Cases will be approached to take part in the study by clinical staff and recruited by the research team. Cases will be recruited either face-to-face during their medical attendance, by telephone if the parent or guardian have given permission to be contacted via this route or by postal recruitment following their attendance. Telephone contacts or postal invitations will be initiated within $72 \mathrm{~h}$ of the medical attendance. One reminder will be sent to people who have not replied to the original postal invitation 2 weeks after the original mailing. Eligibility for the study will be assessed prior to making the approach, based on data recorded in the medical records. Further eligibility assessment will be undertaken when parents return completed questionnaires.

Two sources of controls will be used; matched community controls and unmatched hospital controls. Community controls will be matched on age (within 4 months of the case's age) and sex and recruited from the register of the cases' GP. In all, 10 children will be identified from the register, with the aim of recruiting an average of 4 for each case and a postal invitation will be sent to the parent/guardian by the GP or the Primary Care Trust. One reminder will be sent to non-responders 2 weeks after the original mailing. Where the practices are unwilling or unable to recruit controls, controls will be recruited from the GP practice geographically closest to the cases' GP practice. Controls will be recruited within 4 months of the case injury. Hospital controls will comprise children with a different mechanism of fall injury (ie, stairway, from furniture or on one level) and children participating in two other ongoing case control studies of poisoning and scalds. All hospital controls recruited up to the date of the last case recruited will be used in the analysis. The process of recruitment of cases and controls is shown in figures 1 and 2 .

\section{Definition of exposures}

The time period of interest for assessing exposures is $24 \mathrm{~h}$ preceding the MAFI for cases and the $24 \mathrm{~h}$ prior to completing the questionnaire for controls, see table 1 for exposures specific to each type of fall.

\section{Definition of confounding variables}

Potential confounding variables to be measured include: sociodemographic and economic characteristics (eg, family size and structure, ethnicity, overcrowding, housing tenure, receipt of state-provided means-tested benefits, maternal age) and validated measures of child behaviour and temperament (Infant, Early Child and Child Behaviour Questionnaires (activity and high intensity pleasure subscales)), ${ }^{42-46}$ parenting daily hassles (parenting tasks subscale), ${ }^{47} 48$ mental health (Hospital Anxiety and Depression Scale (HADS)), ${ }^{49}$ general health visual analogue 
Figure 1 Recruitment of cases.

Child has medially attended fall injury

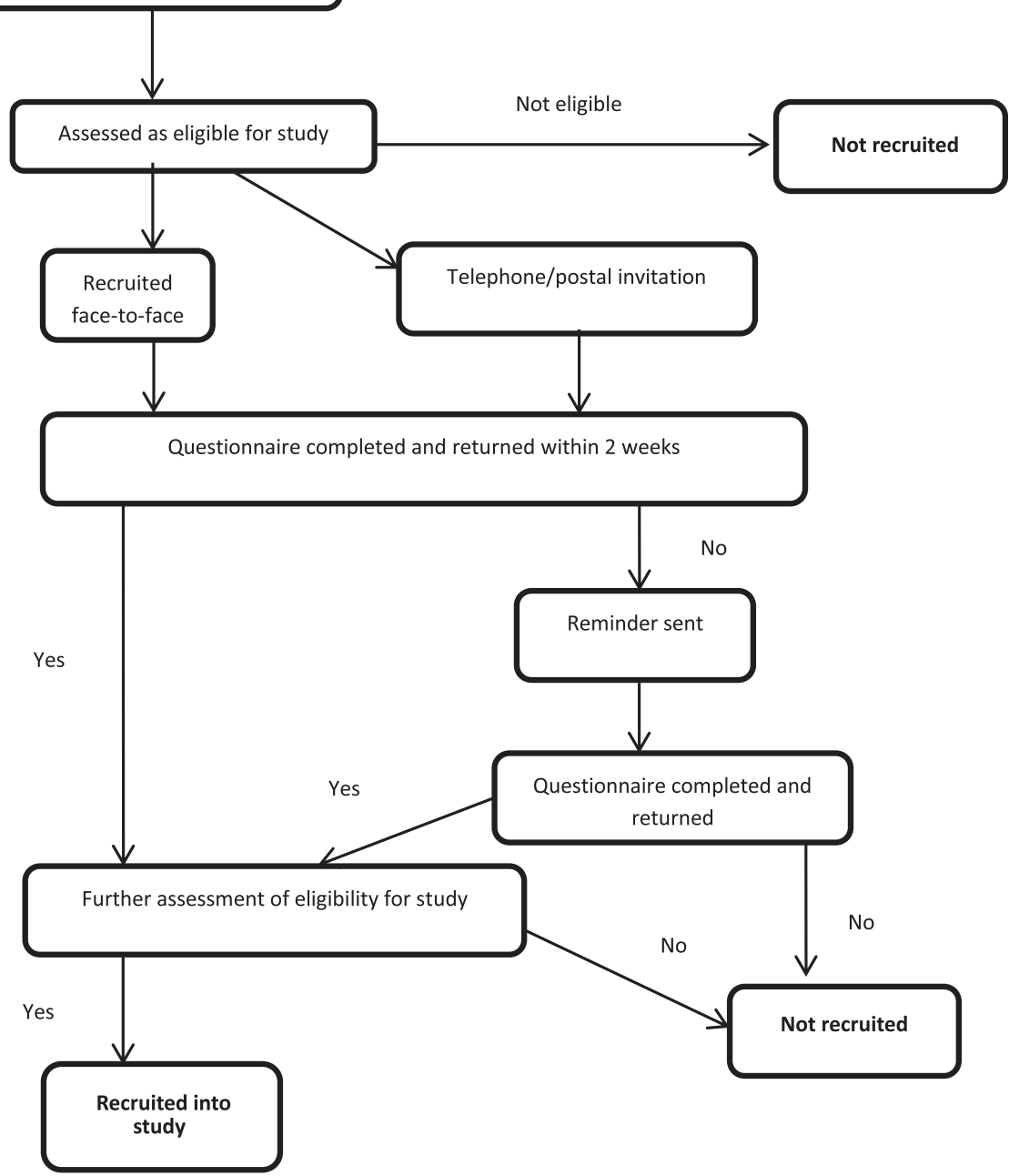

scale, ${ }^{50}$ paediatric quality of life $e^{51}$ and time cared for outside the home and place of out-of-home care.

\section{Measurement of exposures and confounding variables}

Three age-specific questionnaires for completion by parents will be used (age 0-12 months, 13-36 months and 37-59 months), containing previously validated questions wherever possible. Case questionnaires were piloted with families in the paediatric ED in Nottingham University Hospital and control questionnaires were piloted with parents attending children's centres in Nottingham to assess face validity, comprehension, ease and time to completion. To increase response rates, participants returning a completed questionnaire will be sent a $£ 5.00$ (equivalent to US\$7.70 or €6.00) gift voucher for use in local shops. $^{53}$

\section{Validation of exposure measurement}

Parental reported exposures will be validated by home visits to a sample of cases and controls to assess agreement between reported and observed safety behaviours, safety equipment use and home hazards. All parents or guardians participating in the case-control studies will be asked if they are willing to participate in other child safety research projects, one of which is the validation study. Those agreeing will be visited at home as soon as possible after study questionnaires are returned. Home visits will be conducted by trained researchers using a standardised checklist. Participants will be asked if they have made any changes to safety behaviours, safety equipment use or hazards over the preceding 3 months and if changes have been made, what the safety behaviour, safety equipment use or presence of hazards was prior to implementation of change. Researchers conducting home visits will be blind to respondents' questionnaire responses in the case-control study.

\section{ANALYSIS}

\section{Validation of exposure measures}

The sensitivity, specificity, positive and negative predictive values (and 95\% CIs) will be estimated for each safety behaviour, safety equipment used and hazard comparing observations at the validation visit with questionnaire responses.

\section{Case-control studies}

Causal diagrams will be drawn for each falls mechanism to describe interrelationships between variables and distinguish confounding variables and likely effect mediators prior to undertaking analysis. Exposure and confounding variables will be described separately for cases and controls using frequencies and percentages for categorical variables and means (and SDs) or medians (and IOR) for continuous variables, dependent on their distributions. 
Figure 2 Recruitment of controls.

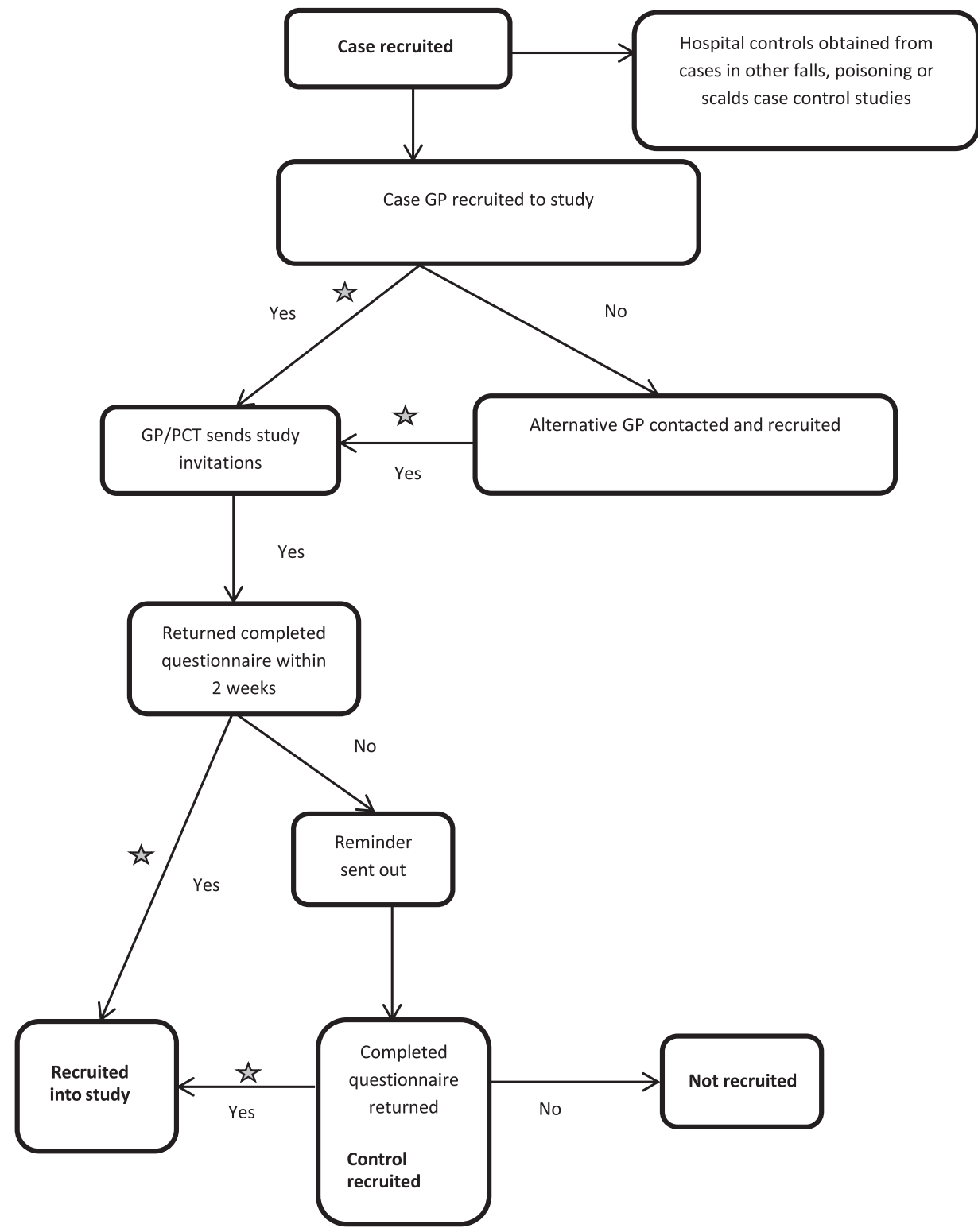

Key:

논 $=$ eligibility assessed

The analysis of cases and matched controls will use conditional logistic regression to estimate ORs and 95\% CI for each fall mechanism, unadjusted and adjusted for confounding variables identified from causal diagrams. Analyses will not be adjusted for effect mediators (ie, variables potentially in the causal chain between exposure and outcome). Where variables are identified as effect modifiers, stratified results will be presented in addition to adjusted results.

The analysis of cases and hospital controls (cases with other injury mechanisms) will use unconditional logistic regression to estimate unadjusted and adjusted ORs for each case control study. As controls are not individually matched to the cases, the analysis will adjust for age, sex, deprivation (measured using the Index of Multiple Deprivation 2010 at super output area level) ${ }^{54}$ and distance from hospital, in addition to other potential confounding variables, which will be included in the models under the conditions discussed above. Where we hypothesise that exposures may be associated with multiple injury mechanisms we will categorise the control groups by injury mecha- nism and estimate separate ORs comparing cases with each of these control groups.

Differential effects by child and family factors and injury severity will be examined by adding interaction terms to logistic regression models.

\section{Sample size}

Validation of exposure measures

A total of 80 participants will allow estimation of $95 \%$ CI of $\pm 20 \%$ around a sensitivity of $80 \%$, assuming a minimum of $20 \%$ of participants observed to have the safety behaviour, safety equipment use or hazard of interest. As it is plausible that sensitivity will vary between cases and controls, 80 cases and 80 controls will be recruited across participating hospitals and MIUs.

\section{Case-control studies}

To detect an OR of 0.7 , based on $80 \%$ power, $5 \%$ significance level, a correlation between matched cases and controls of 0.1 , an average of 4 controls per case and a range of exposure 
Table 1 Exposures of interest for the three falls case control studies

\begin{tabular}{|c|c|c|c|}
\hline & Stairway falls & Falls on one level & Falls from furniture \\
\hline${ }^{*}$ Safety gates on stairs or used elsewhere $† \ddagger \S$ & $\mathrm{x}$ & $\mathrm{x}$ & $\mathrm{x}$ \\
\hline *Baby walkers $†$ & $\mathrm{x}$ & $\mathrm{x}$ & $\mathrm{x}$ \\
\hline *Play pens $\dagger$ & $\mathrm{x}$ & $\mathrm{x}$ & $\mathrm{x}$ \\
\hline *Travel cots $\dagger$ & $\mathrm{x}$ & $\mathrm{x}$ & $\mathrm{x}$ \\
\hline${ }^{*}$ Stationary activity centres $\dagger$ & $\mathrm{x}$ & $\mathrm{x}$ & $\mathrm{x}$ \\
\hline Loose carpets on stairs $† £ \S$ & $\mathrm{x}$ & & \\
\hline *Presence of bannisters and *width of bannister gaps $† \ddagger \S$ & $\mathrm{x}$ & & \\
\hline Lighting on stairs $† \ddagger \S$ & $\mathrm{x}$ & & \\
\hline Tripping hazards on stairs $\dagger \neq \S$ & $\mathrm{x}$ & & \\
\hline $\begin{array}{l}\text { Stairway characteristics (*steepness, width, *landings, } \\
{ }^{*} \text { winding stairs, state of repair of steps and *type of stair coverings) } \dagger \neq \S\end{array}$ & $\mathrm{x}$ & & \\
\hline Rugs or carpets firmly fixed to floor $† \ddagger \S$ & & $\mathrm{x}$ & \\
\hline Electric wires or cables trailing across floors $† \ddagger \S$ & & $\mathrm{x}$ & \\
\hline Bunk beds $† \S$ & & & $\mathrm{x}$ \\
\hline Leaving child unattended on raised surfaces (not in car seat or bouncing cradle) $\dagger \neq \S$ & & & $\mathrm{x}$ \\
\hline Placing car seats or bouncing cradles on raised surfaces $\dagger \neq \S$ & & & $\mathrm{x}$ \\
\hline Frequency of children climbing or playing on furniture $‡ \S \S$ & & & $\mathrm{x}$ \\
\hline Climbing or playing on garden furniture $† \S$ & & & $\mathrm{x}$ \\
\hline Unsupervised playing in the garden†‡§ & & $\mathrm{x}$ & $\mathrm{x}$ \\
\hline \multicolumn{4}{|l|}{ Teaching and following safety rules including: ${ }^{41}$} \\
\hline What to do or not do if the floor is slippery†‡§ & & $\mathrm{x}$ & \\
\hline About running in the house $‡ \S$ & & $\mathrm{x}$ & \\
\hline About jumping on the bed or furniture $† £ \S$ & & & $\mathrm{x}$ \\
\hline What to do or how to behave when going down the stairs $† \ddagger \S$ & $\mathrm{x}$ & & \\
\hline About carrying big things or many things while going down stairs $† \ddagger \S$ & $\mathrm{x}$ & & \\
\hline
\end{tabular}

*Exposures validated by home observation.

†Measured in children aged 0-12 months.

$\neq$ Measured in children aged $13-36$ months.

§Measured in children aged 37-59 months.

prevalences from previous research (use of stairgates (45\%), baby walkers (36\%), playpens (42\%), stationary activity centres $(24 \%)$, stairgates across doors $(30 \%)$, rugs firmly fixed to floors $(54 \%)$, floors clear of tripping hazards $(43 \%)$ and not leaving child unattended on raised surfaces (65\%)), 55 56 each casecontrol study will require 496 cases and 1984 matched controls.

\section{ETHICS COMMITTEE AND REGULATORY APPROVALS}

Ethical approval has been provided by the Nottingham 1 Ethics Committee (reference number: 09/H0407/14). Approval has been obtained from National Health Service Research \& Development Departments providing research governance to participating hospitals and MIUs.

\section{DISCUSSION}

These three falls case control studies will be the largest in the field to date. As they will adjust for a range of potential confounders, validate measures of exposure, investigate modifiable risk factors for specific injury mechanisms and use community and hospital controls, they should address some of the deficiencies of previous observational studies. However, the potential for bias still exists. Selection bias may occur through non-response of cases and controls. Attempts to minimise this include using a piloted questionnaire containing standardised and validated tools, use of incentives for questionnaire completion and reminders. Misclassification bias can arise when participants are incorrectly classified as having or not having an exposure of interest. As our exposures are self-reported and as some responses may be considered by parents as being more socially desirable or acceptable than others, it is possible that parents may over report safety behaviours and safety equipment use and under report hazards. In addition, parental recall of some exposures may be inaccurate. Misclassification occurring differentially between cases and controls can result in biased estimates of effect and not always towards the null value. ${ }^{55}$ Efforts to minimise misclassification bias include the use of nonjudgemental language in the study documentation, time period restrictions for measuring exposures limited to $24 \mathrm{~h}$ prior to injury for cases or $24 \mathrm{~h}$ prior to questionnaire completion for controls, initiating study invitations within $72 \mathrm{~h}$ of the medically attended fall injury and validating exposures in a sample of cases and controls. These multicentre case-control studies should provide evidence on the effect of potentially modifiable risk factors for fall injuries in young children that can be used to develop appropriate public health interventions.

Acknowledgements The Keeping Children Safe Study Group acknowledges the support of the National Institute for Health Research, through the Primary Care Research Network.

Funding This project is funded by a National Institute for Health Research (NIHR) programme grant RP-PG-0407-10231.

Disclaimer This paper presents independent research commissioned by the National Institute for Health Research (NIHR) under its Programme Grants for Applied Research funding scheme (RP-PG-0407-10231). The views expressed in this paper are those of the author(s) and not necessarily those of the NHS, the NIHR or the Department of Health.

Competing interests None. 
Ethics approval Ethics approval was provided by Nottingham 1 Ethics Committee $\mathrm{R} / \mathrm{N}$ - 09/H0407/14

Provenance and peer review Not commissioned; internally peer reviewed. Open Access This is an Open Access article distributed in accordance with the Creative Commons Attribution Non Commercial (CC BY-NC 4.0) license, which permits others to distribute, remix, adapt, build upon this work non-commercially, and license their derivative works on different terms, provided the original work is properly cited and the use is non-commercial. See: http://creativecommons.org/ licenses/by-nc/4.0/

\section{REFERENCES}

1. Runyan C, Casteel C. The State of Home Safety in America: Facts about Unintentional Injuries in the Home. 2nd edn. Washington, DC: Home Safety Council, 2004.

2. Kingma J, Ten Duis HJ. Severity of injuries due to accidental fall across the life span: a retrospective hospital-based study. Percept Mot Skills 2000;90:62-72.

3. Bulut M, Koksal 0, Korkmaz A, et al. Childhood falls: characteristics, outcome, and comparison of the Injury Severity Score and New Injury Severity Score. Emerg Med J 2006;23:540-5

4. Peden M, Oyegbite K, Ozanne-Smith J, et al. World Report on Child Injury Prevention. Geneva: World Health Organization, 2008.

5. Pickett W, Streight S, Simpson K, et al. Injuries experienced by infant children a population-based epidemiological analysis. Pediatrics 2003;111:e365-70.

6. Steenkamp M, Cripps R. Child Injuries Due to Falls (Injury Research and Statistics Series, No. 7). Adelaide: Australian Institute of Health and Welfare, 2001.

7. Khambalia A, Joshi P. Brussoni M, et al. Risk factors for unintentional injuries due to falls in children aged 0-6 years: a systematic review. Inj Prev 2006;12:378-85.

8. Bartlett SN. The problem of children's injuries in low income countries: a review Health Policy Plan 2002:17:1-13.

9. Hawley $\mathbf{C A}$, Ward $\mathrm{AB}$, Long $\mathrm{J}$, et al. Prevalence of traumatic brain injury amongst children admitted to hospital in one health district: a population-based study. Injury 2003:34:256-60.

10. Williamson LM, Morrison A, Stone DH. Trends in head injury mortality among $0-14$ year olds in Scotland (1986-95). J Epidemiol Community Health 2002:56:285-8.

11. Brookes M, Macmillan R, Cully S, et al. Head injuries in accident and emergency departments. How different are children from adults? J Epidemiol Community Health 1990; 44:147-51.

12. Tiret $\mathbf{L}$, Hausherr $\mathrm{E}$, Thicoipe $\mathrm{M}$, et al. The epidemiology of head trauma in Aquitaine (France), 1986: a community-based study of hospital admissions and deaths. Int $J$ Epidemiol 1990;19:133-40.

13. UNICEF. Innocenti Working Papers - Child Mortality and Injury in Asia 2008. http:// www.tasc-gcipf.org/downloads/Innocenti Papers 2008.pdf laccessed 3 Apr 2012).

14. Garrettson LK, Gallagher SS. Falls in children and youth. Pediatr Clin North Am 1985; 32:153-62.

15. Kopjar B, Wickizer TM. Fractures among children: incidence and impact on daily activities. Inj Prev 1998;4:194-7.

16. Rennie L, Court-Brown CM, Mok JY, et al. The epidemiology of fractures in children. Injury 2007;38:913-22

17. Smith MD, Burrington JD, Woolf AD. Injuries in children sustained in free falls: an analysis of 66 cases. J Trauma 1975;15:987-91.

18. Hansoti B, Beattie T. Can the height of a fall predict long bone fracture in children under 24 months? Eur J Emerg Med 2005; 12:285-6.

19. Department of health. Hospital Episode Statistics, 2009-2010. http://www. hesonline.nhs.uk/Ease/servlet/ContentServer?sitelD=1937\&categorylD=211 (accessed 30 Oct 2010).

20. Hyder AA, Sugerman D, Ameratunga $S$, et al. Falls among children in the developing world: a gap in child health burden estimations? Acta Paediatr 2007:96:1394-8.

21. Falls Fact Sheet. The Economic Burden of Unintentional Injury in Canada. Toronto, ON: Smartrisk; Emergency Health Services Branch, Ministry of Health, Ontario, 1998:83

22. Miller TR, Romano ED, Spicer RS. The cost of childhood injury and the value of prevention. 2000;10:137-63.

23. Agran PF, Anderson C, Winn D, et al. Rates of pediatric injuries by 3-month intervals for children 0 to 3 years of age. Pediatrics 2003;111:e683-92

24. Pitone ML, Attia MW. Patterns of injury associated with routine childhood falls. Pediatr Emerg Care 2006:22:470-4.

25. Flavin MP, Dostaler SM, Simpson K, et al. Stages of development and injury patterns in the early years: a population-based analysis. BMC Public Health 2006:6:187.

26. Ozanne-Smith J, Day L, Stathakis V, et al. Community Based Injury Prevention Evaluation Report: Shire of Bulla Safe Living Program. Canberra: Monash University Accident Research Centre, 1994. (Report No. 6).

27. Schelp L, Ekman R, Fahl I. School accidents during a three school-year period in a Swedish municipality. Public Health 1991:105:113-20.

28. Laflamme L, Hasselberg M, Burrows S. 20 Years Of research on socioeconomic Inequality and children's-unintentional injuries Understanding the cause-specific evidence at hand. Int J Pediatr 2010;2010. pii: 819687.

29. Roberts I, Power C. Does the decline in child injury mortality vary by social class? A comparison of class specific mortality in 1981 and 1991. BMJ 1996;313:784-6.

30. Laursen B, Nielsen JW. Influence of sociodemographic factors on the risk of unintentional childhood home injuries. Eur J Public Health 2008;18:366-70
31. Azizi BH, Zulkifli HI, Kassim MS. Circumstances surrounding accidental poisoning in children. Med J Malaysia 1994;49:132-7

32. Elkington J, Blogg S, Kelly J, et al. Head injuries in infants: a closer look at babywalkers, stairs and nursery furniture. NSW Health Bulletin 1999;10:82-3.

33. LeBlanc JC, Pless IB, King WJ, et al. Home safety measures and the risk of unintentional injury among young children: a multicentre case-control study. CMAJ 2006;175:883-7.

34. Petridou E, Kouri N, Polychronopoulou A, et al. Risk factors for childhood poisoning a case-control study in Greece. Inj Prev 1996;2:208-11.

35. Petridou E, Trichopoulos D, Mera E, et al. Risk factors for childhood burn injuries: a case-control study from Greece. Burns 1998:24:123-8.

36. van Rijn OJ, Bouter $L M$, Kester $A D$, et al. Aetiology of Burn Injuries Among Children Aged 0-4 years: results of a case-control study. Burns 1991;17:213-19.

37. Thompson DC, Rivara FP, Thompson R. Helmets for preventing head and facia injuries in bicyclists. Cochrane Database Syst Rev 2000;(2):CD001855. Review.

38. Runyan CW, Bangdiwala SI, Linzer MA, et al. Risk factors for fatal residential fires N Engl J Med 1992:327:859-63.

39. Kendrick D, Coupland C, Mulvaney C, et al. Home safety education and provision of safety equipment for injury prevention. Cochrane Database Syst Rev 2007;(1): CD005014.

40. WHO. Violence and Injury Prevention and Disability (VIP). http://www.who.int/ violence injury prevention/other injury/falls/en/index.html (accessed $10 \mathrm{Apr}$ 2011).

41. Morrongiello BA, Midgett C, Shields R. Don't run with scissors: young children's knowledge of home safety rules. J Pediatr Psychol 2001;26:105-15.

42. Gartstein MA, Rothbark MK. Studying infant temperament via the Revised infant behavior questionnaire. Infant Behav Dev 2003:26:64-86.

43. Putnam SP, Gartstein MA, Rothbart MK. Measurement of fine-grained aspects of toddler temperament: the early childhood behavior questionnaire. Infant Behav Dev 2006;29:386-401.

44. Putnam SP, Rothbart MK. Development of short and very short forms of the Children's Behavior Questionnaire. J Pers Assess 2006;87:102-12.

45. Morrongiello BA, Lasenby-Lessard J. Psychological determinants of risk taking by children: an integrative model and implications for interventions. Inj Prev 2007:13:20-5

46. Plumert JM, Schwebel DC. Social and temperamental influences on children's overestimation of their physical abilities: links to accidental injuries. J Exp Child Psychol 1997;67:317-37.

47. Crnic KA, Booth CL. Mothers' and fathers' perceptions of daily hassles of parenting across early childhood. J Marriage Fam 1991;53:1043-50.

48. Crnic KA, Greenberg MT. Minor parenting stresses with young children. Child Dev 1990;61:1628-37.

49. Bjelland I, Dahl AA, Haug $\Pi$, et al. The validity of the Hospital Anxiety and Depression Scale. An updated literature review. J Psychosom Res 2002;52:69-77. Review.

50. Brunner HI, Maker D, Grundland B, et al. Preference-Based measurement of healthrelated quality of life (HROL) in children with Chronic Musculoskeletal Disorders (MSKDs). Med Decis Making 2003;23:314-22.

51. Varni JW, Seid M, Kurtin PS. PedsQL(TM) 4.0: reliability and validity of the Pediatric Quality of Life Inventory version 4.0 generic core scales in healthy and patient populations. Med Care 2001:39:800-12.

52. Varni JW, Seid M, Rode CA. The PedsQL: measurement model for the pediatric quality of life inventory. Med Care 1999;37:126-39.

53. Edwards $\mathbf{P}$, Roberts I, Clarke $\mathrm{M}$, et al. Methods to increase response rates to posta questionnaires. Cochrane Database Syst Rev 2007;(2):MR000008.

54. Directgov. The English Indices of Deprivation. 2010. http://www.imd.communities. gov.uk (accessed 2 Jun 2011).

55. Clamp M, Kendrick D. A randomised controlled trial of general practitioner safety advice for families with children under 5 years. BMJ 1998;316:1576-9.

56. Watson M, Kendrick D, Coupland C, et al. Providing child safety equipment to prevent injuries: randomised controlled trial. BMJ 2005;330:178

57. Jurek AM, Greenland S, Maldonado G, et al. Proper interpretation of non-differentia misclassification effects: expectations vs observations. Int J Epidemiol 2005;34:680-7.

\section{APPENDIX 1}

\section{The Keeping Children Safe Study Group}

Bristol: Toity Deave ${ }^{1}$, Trudy Goodenough ${ }^{1}$, Bryony Kay

Child Accident Prevention Trust: Mike Hayes ${ }^{3}$

Derby: Joanne Culshaw ${ }^{4}$, Susie Hewitt ${ }^{4}$, Liz Richardson ${ }^{4}$, Rosemary Smith ${ }^{4}$

Great Yarmouth: Donna Wade ${ }^{5}$, Patricia Hagan ${ }^{5}$, Patricia Barclay ${ }^{5}$

Newcastle: Adrian Hawkins ${ }^{6}$, Paul Hindmarch ${ }^{6}$

Norwich: Gosia Majsak-Newman ${ }^{7}$, Clare Ferns ${ }^{7}$, Nathalie Horncastle ${ }^{8}$, Emma

Rayfield ${ }^{9}$, Barbara Stewart ${ }^{9}$

Nottingham: Joanne Ablewhite ${ }^{10}$, Isobel Allwood ${ }^{11}$, Natasha Barnes ${ }^{11}$, Penny Benford $^{10}$, Clare Bryan ${ }^{12}$, Philip Miller ${ }^{11}$, Lindsey Pearson ${ }^{11}$, Persephone Wynn ${ }^{10}$, Ben Young ${ }^{10}$

${ }^{1}$ Centre for Child \& Adolescent Health, University of the West of England, Bristol,

Oakfield House, Oakfield Grove, Bristol BS8 2BN, UK

${ }^{2}$ Emergency Department, United Bristol Healthcare Trust, Bristol Royal Infirmary, Upper Maudlin Street, Bristol, BS2 8HW, UK 
${ }^{3}$ Child Accident Prevention Trust, Child Accident Prevention Trust, Canterbury Court (1.09), 1-3 Brixton Road, London SW9 6DE, UK

${ }^{4}$ Derby Hospitals NHS Foundation Trust, Royal Derby Hospital, Uttoxeter Road, Derby DE22 3NE, UK

${ }^{5}$ James Paget University Hospital, Lowestoft Road, Gorleston, Great Yarmouth, Norfolk, NR31 6LA, UK

${ }^{6}$ Newcastle Upon Tyne Hopsitals Foundation Trust, Great North Childrens Hospital, Research Unit, Level 2, New Victoria Wing, Royal Victoria Infirmary, Queen Victoria Road, Newcastle-upon-Tyne, NE1 4LP, UK

${ }^{7}$ Norfolk and Norwich University Hospitals NHS Trust, Colney Lane, Norwich, NR4 7UY, UK
${ }^{8}$ Faculty of Medicine and Health Sciences, University of East Anglia, Norwich NR4 7TJ, UK

${ }^{9}$ Norfolk, Great Yarmouth and Waveney Primary Care Research Network, NHS Norfolk, Lakeside 400, Broadland Business Park, Norwich, NR7 OWG, UK

${ }^{10}$ Division of Primary Care, Tower Building, University Park, Nottingham, NG7 2RD, UK

${ }^{11}$ Nottingham University Hospitals NHS Trust, Queen's Medical Centre, Nottingham, NG7 2UH, UK

${ }^{12}$ Nottinghamshire Healthcare Trust, Nottinghamshire Healthcare NHS Trust, 2nd Floor, Duncan Macmillan House, Porchester Road, Mapperley, Nottingham NG3 6AA UK 


\section{Correction}

Kendrick D, Maula A, Stewart J, et al. Keeping children safe at home: protocol for three matched caseecontrol studies of modifiable risk factors for falls. Injury Prevention 2012;18:e3. doi:10.1136/ injuryprev-2012-040394. This article has been made Open Access, with CC-BY license.

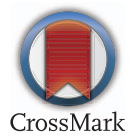

Inj Prev 2015;21:70.

doi:10.1136/injuryprev-2012-040394corr1 